\title{
Electrocardiographic features of hyperkalemia during acute kidney injury in a patient with pacemaker
}

\author{
Alfonso Sforza, Federica De Pisapia, Giuliano De Stefano, Antonio Gaspardini, Maria Immacolata Arnone, \\ Andrea D’Amato, Maria Viviana Carlino, Costantino Mancusi \\ Hypertension Research Center, UOC Emergency Medicine, Federico II University Hospital, Naples, Italy
}

\begin{abstract}
We describe a case of a 79-year-old man with pacemaker who presented to the Emergency Department due to asthenia and acute confusional state. He had a history of atrial fibrillation, anemia and colostomy and he was on treatment with diuretics. The electrocardiogram (ECG) showed pacemaker-induced ventricular activity, QRS complexes excessively wide with sinewave appearance, tall and peaked T waves, without electrically evident atrial activity. Potassium concentration on arterial blood gas analysis was $8.8 \mathrm{mmol} / \mathrm{L}$. ECG abnormalities disappeared after therapy with calcium chloride and spontaneous cardiac activity reappeared.
\end{abstract}

\section{Introduction}

Hyperkalemia, defined as a serum potassium level above $5.5 \mathrm{mEq} / \mathrm{L}$, may affect up to $10 \%$ of all hospitalized patients and, in most cases, it is due to medications and renal insufficiency. Hyperkalemia may have dramatic effects on cardiac electrical activity that must be recognized and promptly treated to avoid cardiac arrest. ${ }^{1}$ The electrocardiographic changes due to hyperkalemia can be difficult to interpret in patients with pacemaker-dependent cardiac activity.

Correspondence: Costantino Mancusi, Hypertension Research Center, Federico II University Hospital, via Pansini 5, 80131 Naples, Italy.

Tel.: +39.081.7462013.

E-mail: costantino.mancusi@unina.it

Key words: Hyperkalemia; implantable medical devices; electrocardiography; calcium chloride therapy; kidney disease.

Contributions: AS and FDP conceived the paper and wrote the manuscript; CM, MVC, AG, MIA, GDS and AD'A contributed to the discussion and edited the manuscript.

Conflict of interest: the authors declare no potential conflict of interest.

Received for publication: 19 January 2018.

Accepted for publication: 12 February 2018.

This work is licensed under a Creative Commons Attribution NonCommercial 4.0 License (CC BY-NC 4.0).

CCopyright A. Sforza et al., 2018

Licensee PAGEPress, Italy

Italian Journal of Medicine 2018; 12:145-147

doi:10.4081/itjm.2018.986

\section{Case Report}

A 79-year-old man presented to the Emergency Room with new onset of pronounced asthenia and acute confusional state. We assigned him a yellow triage-tag and we collected data of his pathological history. He had a pacemaker, a history of atrial fibrillation, anemia and he wore a colostomy bag. He denied allergies. He was on treatment with diuretics, new oral anticoagulant, $\beta$-blocker, vitamin supplements and iron. On physical examination he was alert and confused. At admission blood pressure was $90 / 50 \mathrm{mmHg}$, heart rate was 85 beats per minute, oxygen saturation was $97 \%$ in room air, respiratory rate was 22 breaths per minute and he was afebrile. Chest examination revealed normal vesicular murmur. Cardiovascular examination revealed muffled heart sounds, normal peripheral pulses, no edema. Abdominal examination was normal. Neurologic exam showed confusion and no focal signs. Electrocardiogram (ECG) showed no organized $\mathrm{P}$ waves with failure of atrial pacemaker capture, ventricular activity under pacing with extremely large QRS complexes $(240 \mathrm{~ms})$ and symmetrically peaked $\mathrm{T}$ waves configuring a sine-wave pattern particularly evident in precordial leads (Figure 1). Blood gas analysis showed severe hyperkalemia and metabolic acidosis (Table 1). Calcium chloride 1 gram was promptly administrated ev over 2 min, followed by $250 \mathrm{~mL}$ of $10 \%$ dextrose plus insulin 10 units and bicarbonate infusion of $50 \mathrm{mEq}$. After the first infusion QRS complex promptly narrowed (Figure 2). Laboratory test showed an acute kidney injury and confirmed severe hyperkalemia (Table 2). The patient underwent then urgent hemodialysis and he was admitted to sub intensive care unit. 


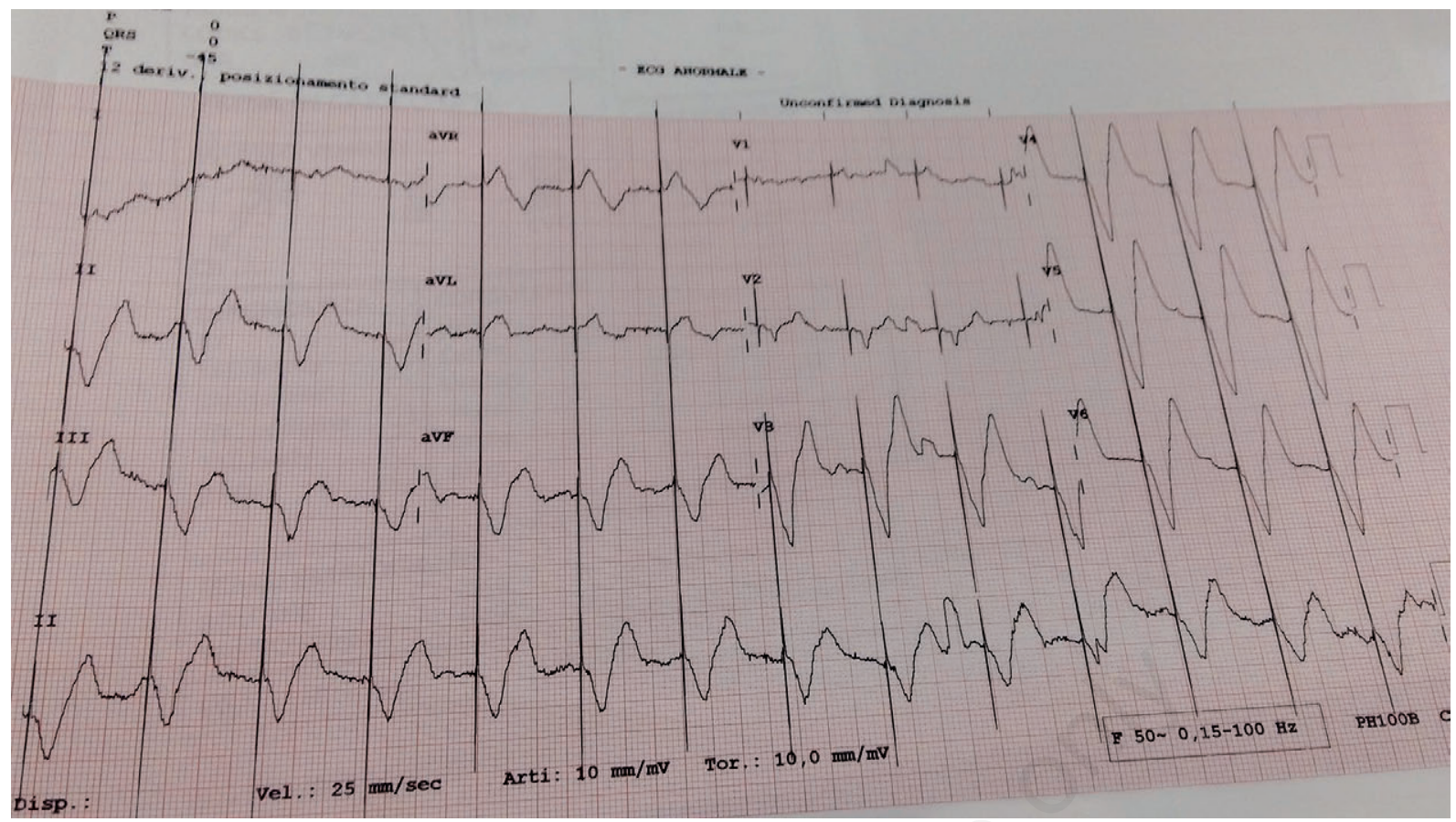

Figure 1. First electrocardiogram showing absent $P$ wave, extremely large paced $Q R S$ complex with a sine-wave pattern.

\section{Discussion}

While mild hyperkalemia is usually asymptomatic, high levels of potassium may cause life-threatening cardiac arrhythmias, muscle weakness and paralysis. Symptoms usually develop for values higher than 6.5$7 \mathrm{mEq} / \mathrm{L}$, but the rate of change is more important than the numerical value. ${ }^{1}$ Homeostasis of potassium is primary due to kidneys function, with a small contribution of the gastrointestinal tract. Hyperkalemia is most commonly encountered in patients with decreased kidney function. ${ }^{2}$ Increases in total body potassium may have dramatic effects on the

Table 1. Blood gas analysis in room air.

\begin{tabular}{lcc}
\hline Parameter & Value & Unit of measure \\
\hline $\mathrm{pH}$ & 7.16 & \\
\hline $\mathrm{pCO}_{2}$ & 18 & $\mathrm{mmHg}$ \\
\hline $\mathrm{pO}_{2}$ & 114 & $\mathrm{mmHg}$ \\
\hline $\mathrm{Na}^{+}$ & 128 & $\mathrm{mmol} / \mathrm{L}$ \\
\hline $\mathrm{K}^{+}$ & 8.8 & $\mathrm{mmol} / \mathrm{L}$ \\
\hline $\mathrm{Ca}^{++}$ & 1.41 & $\mathrm{mmol} / \mathrm{L}$ \\
\hline $\mathrm{Glu}^{+}$ & 99 & $\mathrm{mg} / \mathrm{dL}$ \\
\hline $\mathrm{Lat}^{-}$ & 0.4 & $\mathrm{mmol} / \mathrm{L}$ \\
\hline $\mathrm{HCO}_{3}^{-}$ & 6.4 & $\mathrm{mmol} / \mathrm{L}$ \\
\hline $\mathrm{SO}_{2}$ & 97 & $\%$ \\
\hline $\mathrm{Hb}^{-}$ & 11.8 & $\mathrm{~g} / \mathrm{dL}$ \\
\hline
\end{tabular}

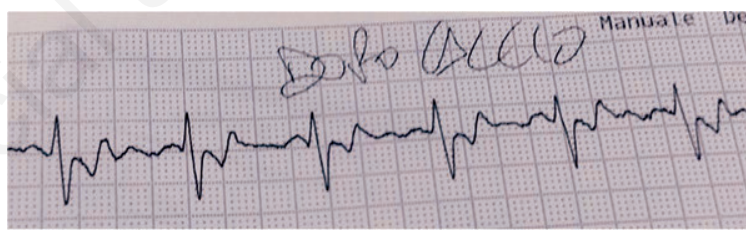

Figure 2. Electrocardiogram after calcium administration showing reappearance of atrial activity and narrow QRS.

Table 2. Laboratory tests.

\begin{tabular}{lcc}
\hline Parameter & Value & Unit of measure \\
\hline Red blood cells & 4.46 & $\times 10^{6} / \mathrm{mL}$ \\
\hline Hemoglobin & 14 & $\mathrm{~g} / \mathrm{dL}$ \\
\hline Hematocrit & 42.1 & $\%$ \\
\hline Platelets & 204 & $\times 10^{3} / \mathrm{mL}$ \\
\hline White blood cells & 7.3 & $\times 10^{3} / \mathrm{mL}$ \\
\hline Neutrophils & 5.14 & $\times 10^{3} / \mathrm{mL}$ \\
\hline Glucose & 78 & $\mathrm{mg} / \mathrm{dL}$ \\
\hline Urea & 260 & $\mathrm{mg} / \mathrm{dL}$ \\
\hline Creatinine & 3.32 & $\mathrm{mg} / \mathrm{dL}$ \\
\hline Sodium & 131 & $\mathrm{mEq} / \mathrm{L}$ \\
\hline Potassium & 8.8 & $\mathrm{mEq} / \mathrm{L}$ \\
\hline Calcium & 10 & $\mathrm{mg} / \mathrm{dL}$ \\
\hline AST & 19 & $\mathrm{UI} / \mathrm{L}$ \\
\hline ALT & 9 & $\mathrm{UI} / \mathrm{L}$ \\
\hline Bilirubin & 0.43 & $\mathrm{mg} / \mathrm{dL}$ \\
\hline
\end{tabular}


electrocardiogram. The most common changes associated with hyperkalemia are tall, peaked $\mathrm{T}$ waves, reduced amplitude and eventually loss of the $P$ waves, PR prolongation, and marked widening of the QRS complexes. Death resulting from hyperkalemia may be due to asystole, ventricular fibrillation, or a wide pulseless idioventricular rhythm. ${ }^{3}$ In patients with pacemakers, hyperkalemia can cause three important abnormalities that usually become manifest when the $\mathrm{K}^{+}$level exceeds $7 \mathrm{mEq} / \mathrm{L}$ : i) widening of the paced QRS complex from delayed intraventricular conduction velocity; ii) increased atrial and ventricular pacing thresholds, that may cause failure to capture; iii) increased latency manifested by a greater delay of the interval from the pacemaker stimulus to the onset of depolarization. ${ }^{4}$

The urgency of early management for hyperkalemia depends on how rapidly the condition develops, the absolute serum potassium level, the degree of symptoms and the cause. Patients with neuromuscular weakness, paralysis or ECG changes and elevated potassium should receive aggressive treatment. Exogenous sources of potassium should be immediately discontinued. Calcium therapy will stabilize the cardiac response to hyperkalemia and should be initiated immediately in the setting of cardiac toxicity. Calcium does not alter the serum concentration of potassium but is the first-line therapy in hyperkalemia related arrhythmias and ECG changes due to its ability to stabilize cardiomyocyte membranes. Insulin and glucose will drive the potassium back into the cells, effectively lowering serum potassium. $\beta-2$ adrenergic agents such as albuterol will also shift potassium intracellularly. Sodium bicarbonate infusion may be helpful in patients with metabolic acidosis. Loop or thiazide diuretics may be helpful in enhancing potassium excretion but they may be used in non-oliguric and normally hydrated patients. Gastrointestinal cation exchangers such as patiromer may be helpful. Hemodialysis should be performed when indicated. ${ }^{1}$

\section{Conclusions}

An ECG and a blood gas analysis should be obtained at an early stage in patients with pronounced asthenia. An acute kidney injury should be suspected in case of metabolic acidosis. ECG features of hyperkalemia may be difficult to identify in patients with implantable medical devices. The knowledge of electrocardiographic features of hyperkalemia in a patient with paced cardiac activity is essential to promptly administrate calcium chloride therapy and avoid cardiac arrest.

\section{References}

1. Barold SS. The effect of hyperkalaemia on cardiac rhythm devices. Europace 2014;16:467-76.

2. Palmer BF. Diagnosis and treatment of hyperkalemia. Cleve Clin J Med 2017;84:934-42.

3. Simon LV. Hyperkalemia. Treasure Island (FL): StatPearls Publishing; 2017.

4. Slovis C. ABC of clinical electrocardiography: conditions not primarily affecting the heart. BMJ 2002;324:1320-3. 